\title{
Strategic alliances
}

\author{
Stephen Hancocks OBE \\ Editor-in-Chief
}

The BDJ Upfront section includes editorials, letters, news, book reviews and interviews. Please direct your correspondence to the News Editor,

Kate Quinlan at BDJNews@nature.com. Press releases or articles may be edited, and should include a colour photograph if possible.

S ome few years ago when I was involved in oral health promotion the two words strategic and alliance became conjoined as something of a buzz-phrase. It was used to mean the creation of collaboration between different agencies and groups but I always felt that there was a slight reticence contained within it. A hint of grudging realism that there were occasions when two potential partners had some common ground but that one was strategically using the other for their own ends. Perhaps I was being too picky. I recall my English teacher at secondary school telling me not to be so censorious: and then having to go and look it up. He meant cynical.

Be that as it may, there are many times in the course of life when we need to form alliances or partnerships. Good partnerships whether social or business are at least mutually beneficial but can also spread their advantages more widely, creating virtuous circles. I think it is fair to say that in dentistry we have been historically somewhat suspicious when it comes to trusting others. Perhaps this has been born out of guarding our professionalism as individuals or possibly being wary of straddling the divide between the business of dentistry and the provision of oral healthcare. Certainly the growing trend away from solo practices, which began in the last century, has meant that we have had to forge agreements in order to realistically survive. I am sure that that development will continue since there is little if anything on the horizon to suggest a return to the single practitioner model from which dentistry first grew.

We have many needs and obligations to fulfil and in order to do this we require a variety of partners in different fields. The dental industry is an excellent example. While on the one hand we have our lingering suspicions over the financial motive (but ask someone in the dental industry and they will say the same about us) unquestionably we could not do what we each do without the other. The upcoming BDIA Dental Showcase at Excel, London provides a further instance of mutual benefit, offering the opportunity for dental professionals to see, discuss and order new products, with profits from this being reinvested in the dental world. The BDA's British Dental Conference provides a similar opportunity for the two strategically aligned organisations to synergistically offer members advantages for the furtherance of their practices and patient care. But this also highlights where non-strategic partnerships simply redundant. The research and development of preventive products relies on the funding invested by large companies, often in university or dental school settings and this too adds to the strategic interrelationship between the various players.

Funding for post-graduate education also arises from this route in the form of sponsorship for seminars, courses and conferences; fewer of which would be viable without this support, or, conversely, much more expensive to attend. Similarly, this issue of the $B D J$ is one of the biggest ever thanks to the advertis-

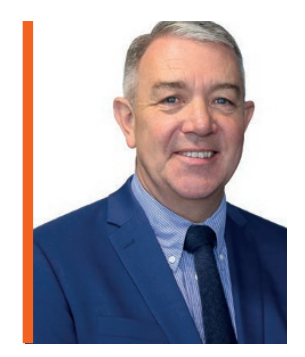

\section{'In dentistry we have been somewhat suspicious when it comes to trusting others...'}

might apply. Although other dentistry shows are available not all are comparable and indeed, in terms of strategic alliances have little to offer. Such events seem increasingly to challenge, by both proximity of dates and use of venues. Potential attendees please note.

As far as the BDA and BDIA are concerned there are other areas of co-operation which serve to mutual advantage. The ongoing campaign against counterfeit dental equipment being a prime example. With specific companies there are also great benefits to be secured. This month is Oral Health Month, a partnership between the BDA and Colgate, neatly celebrated by a sample tube of toothpaste on the cover of this issue. The unarguable value of preventive oral hygiene products readily available to our patients has helped in the improvement of oral health in the UK in recent years. Without toothpastes, brushes, rinses and all manner of other aids our clinical work would be at best a waste of effort and at worst, ers wishing to promote their products and services ahead of BDIA Dental Showcase, which in turn boosts income for the Journal and thus for the BDA.

Building strategic alliances is all well and good providing that one has a strategy. Looking back to the single-handed practitioner of yore the strategy was relatively simple in that it aimed to make a living while serving patients. In the twenty-first century matters have moved on and strategy requires a far greater degree of sophistication and detailed planning. What has not changed is human interaction and the need for trust and shared objectives. These values will continue to be the cornerstones of professional relationships, business development and, specifically in our case, patient care. The creation of strategic alliances is central to all these activities and thinking of them as positive and constructive actions will serve us well.

DOI: 10.1038/sj.bdj.2016.659 